\title{
EDITORIAL
}

\section{A message on the lips}

\author{
M.M. Hoeper* and M. Humbert"
}

r ew systemic diseases present with such a diversity of cardiopulmonary manifestations as hereditary haemorrhagic telangiectasia (HHT), also known as Osler's disease or Rendu-Osler-Weber syndrome. HHT is one of the most common inherited diseases, with a prevalence of one in $5,000-10,000$, and has been linked to mutations in at least five different genes, including endoglin and activated-receptor-like kinase (Alk)-1, both belonging to the transforming growth factor (TGF)- $\beta$ superfamily of receptors [1]. Alk- 1 and endoglin are abundantly expressed on endothelial cells and are involved in mediating the cellular effects of TGF- $\beta$ and other members of the TGF- $\beta$ superfamily. Loss-of-function mutations in the genes encoding for Alk-1 or endoglin cause the clinical syndrome of HHT, which is characterised by vascular dysplasia. The cardinal clinical features of HHT include mucocutaneous telangiectases, often prominently visible on the lips and tongue, and arteriovenous malformations (AVMs), which can involve several organs, such as liver, brain and lungs. Pulmonologists will encounter three main manifestations of HHT: pulmonary arterial hypertension; high cardiac output failure in the setting of large AVMs in the liver; and pulmonary AVMs. A forthcoming article by FAUGHNAN et al. [2], as part of the European Respiratory Journal's (ERJ) current series on pulmonary hypertension [2-7], will review the cardiopulmonary manifestations of HHT in detail.

Pulmonary arterial hypertension and liver AVMs are predominantly seen in patients with Alk-1 mutations (also called HHT type 2) [8]. Isolated pulmonary arterial hypertension in patients with HHT is clinically and histologically indistinguishable from idiopathic pulmonary arterial hypertension, a disease that has been linked to mutations in another TGF- $\beta$ superfamily receptor, termed bone morphogenetic protein receptor-II [9]. Many patients with HHT type 2, however, present with a distinct clinical picture, characterised by pulmonary hypertension and a state of high cardiac output caused by liver AVMs [10]. These patients are prone to developing refractory heart failure within weeks to months after presentation. Treating this condition is a major challenge and successful therapy often requires a combined approach, with embolisation of the liver AVMs to bring cardiac output

*Dept of Respiratory Medicine, Hannover Medical School, Hannover, Germany. \#Université ParisSud 11, Service de Pneumologie, Hôpital Antoine-Béclère, Assistance Publique Hôpitaux de Paris Clamart, France.

STATEMENT OF INTEREST: None declared.

CORRESPONDENCE: M.M. Hoeper, Dept of Respiratory Medicine, Hannover Medical School, CarlNeuberg-Straße 1, 30625 Hannover, Germany. Fax: 49 5115328536. E-mail: hoeper.marius@mhhannover.de back to a normal level [11] together with medical therapy of pulmonary hypertension.

Pulmonary AVMs are another manifestation of HHT, occurring most often in patients with endoglin mutations (HHT type 1). With careful screening, including chest radiography, computed tomography and contrast echocardiography, pulmonary AVMs may be found in up to $50 \%$ of HHT patients (fig. 1) [12]. These AVMs originate from the pulmonary rather than the bronchial arteries and are associated with the signs and complications of intrapulmonary right-to-left shunts. Smaller pulmonary AVMs are often clinically silent until the patients present with neurological catastrophes, such as ischaemic strokes or brain abscesses. Larger pulmonary AVMs can result in hypoxaemia and reduced exercise capacity. Rarely, patients present with massive haemoptysis or rupture as life-threatening complications of pulmonary AVMs. However, all these problems are preventable, as embolotherapy offers a safe and effective means of sealing pulmonary AVMs before they cause irreversible problems. Thus, screening HHT patients for pulmonary AVMs should be advocated. In a recent study, SHovlin et al. [13] studied 305 patients with HHT, of whom the vast majority $(\mathrm{n}=219 ; 72 \%)$ were found to have pulmonary AVMs. Almost $80 \%$ of these patients had no respiratory symptoms and nearly half of the AVMs were detected by screening programmes involving not only affected patients but also their family members. Additionally, 74 (34\%) individuals had a neurological event, i.e. a stroke or a brain abscess, underscoring the magnitude of the problem. In contrast, not a single neurological event occurred in those patients in whom all visible pulmonary AVMs had been successfully treated by embolotherapy. These data provide a strong argument for establishing screening programmes and pre-emptive treatment strategies in HHT patients.

However, given the fact that HHT patients are prone to develop pulmonary hypertension, there is concern that embolisation of pulmonary AVMs increases pulmonary artery pressure, which could have devastating consequences in patients presenting with established pulmonary hypertension. In the present issue of the ERJ, SHOVLIN et al. [14] present somewhat reassuring data derived from 143 patients with pulmonary AVMs (of whom 131, i.e. $92 \%$, had HHT) treated with embolisation. No patient developed signs of right heart failure and there was not a single case where the pulmonary artery pressure rose significantly.

Does this mean that worsening pulmonary hypertension is not a matter of concern when pulmonary AVMs are embolised in patients with HHT? Certainly not! While the study by 


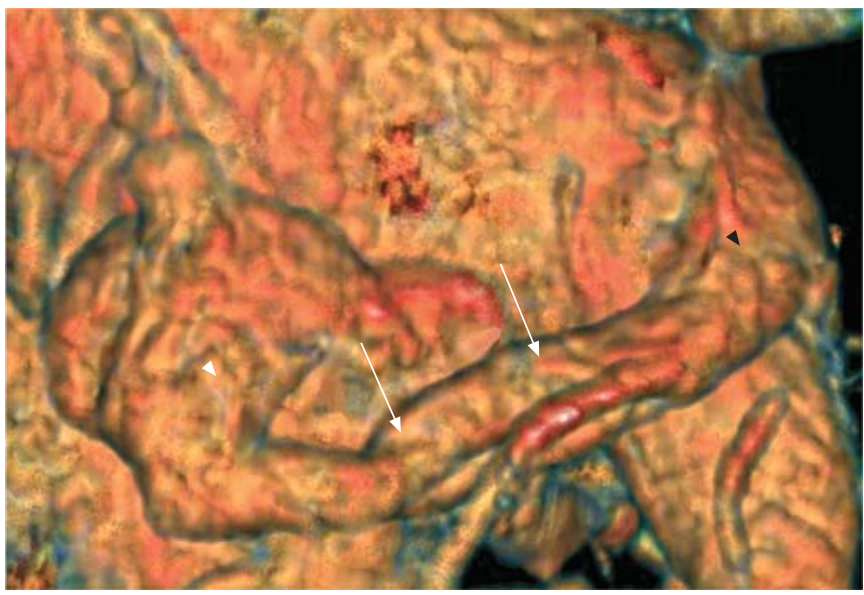

FIGURE 1. Three-dimensional reconstruction of computed tomography angiography (64 row technique), showing a large pulmonary arteriovenous malformation (arrows) connecting the trunk of the right pulmonary artery (white arrowhead) with the right upper lobe vein (black arrowhead). The 32-yr-old patient had a family history of hereditary haemorrhagic telangiectasia and presented with repeated bouts of life-threatening haemoptysis and hypoxaemia due to right-to-left shunting. No further pulmonary arteriovenous malformations were identified. The patient was treated with embolisation, after which blood gases normalised and no further haemoptysis occurred.

SHOVLIN et al. [14] presents unique data, its main shortcoming is that it did not include patients with advanced pulmonary hypertension and signs of right heart failure. In fact, four patients presenting with a diagnosis of severe pulmonary hypertension were not considered candidates for embolotherapy. In addition, the study looked at only pulmonary artery pressures and not at complete haemodynamics. A patient with an elevated pulmonary artery pressure in the setting of a high cardiac output (i.e. with low pulmonary vascular resistance) will probably tolerate embolisation of pulmonary AVMs, whereas the same procedure may be detrimental in a patient with similar pulmonary artery pressures but a low cardiac output (i.e. a high pulmonary vascular resistance). In the latter patient, embolisation of pulmonary AVMs may result in a critical increase in right ventricular afterload [15]. Thus, from the studies by SHOVLIN and co-workers [13, 14], we can be confident that embolotherapy is a safe and effective means of treating pulmonary AVMs in the majority of HHT patients, but we still don't know if this is also true for the subset of patients with severe pulmonary hypertension.

Nevertheless, important messages can be derived from the studies by SHOVLIN and co-workers [13, 14]: pulmonary arteriovenous malformations are common in patients with hereditary haemorrhagic telangiectasia, but they are often clinically silent. Screening patients and their next of kin for the presence of pulmonary arteriovenous malformations does make a difference, since safe and effective interventions can be offered to prevent the occurrence of devastating complications. Thus, the next time we encounter a patient with telangiectases on the lips (or elsewhere), we should take a closer look.

\section{REFERENCES}

1 Guttmacher AE, Marchuk DA, White RI Jr. Hereditary hemorrhagic telangiectasia. N Engl J Med 1995; 333: 918-924.

2 Faughnan M, Young L, Granton J. The pulmonary vascular complications of hereditary haemorrhagic telangiectasia. Eur Respir J 2008; (in press).

3 Hoeper MM, Dinh-Xuan AT. Pulmonary hypertension: basic concepts and practical management. Eur Respir J 2008; 31: 236-237.

4 Dupuis J, Hoeper MM. Endothelin receptor antagonists in pulmonary arterial hypertension. Eur Respir J 2008; 31: 407-415.

5 Gomberg-Maitland M, Olschewski H. Prostacyclin therapies for the treatment of pulmonary arterial hypertension. Eur Respir J 2008; 31: 891-901.

6 Wilkins MR, Wharton J, Grimminger F, Ghofrani HA. Phosphodiesterase inhibitors for the treatment of pulmonary hypertension. Eur Respir J 2008; 32: 198-209.

7 Behr J, Ryu JH. Pulmonary hypertension in interstitial lung disease. Eur Respir J 2008; 31: 1357-1367.

8 Trembath RC, Thomson JR, Machado RD, et al. Clinical and molecular genetic features of pulmonary hypertension in patients with hereditary hemorrhagic telangiectasia. N Engl J Med 2001; 345: 325-334.

9 Deng Z, Morse JH, Slager SL, et al. Familial primary pulmonary hypertension (gene PPH1) is caused by mutations in the bone morphogenetic protein receptor-II gene. Am J Hum Genet 2000; 67: 737-744.

10 Garcia-Tsao G, Korzenik JR, Young L, et al. Liver disease in patients with hereditary hemorrhagic telangiectasia. N Engl J Med 2000; 343: 931-936.

11 Chavan A, Caselitz M, Gratz KF, et al. Hepatic artery embolization for treatment of patients with hereditary hemorrhagic telangiectasia and symptomatic hepatic vascular malformations. Eur Radiol 2004; 14: 2079-2085.

12 Cottin V, Plauchu H, Bayle JY, Barthelet M, Revel D, Cordier JF. Pulmonary arteriovenous malformations in patients with hereditary hemorrhagic telangiectasia. Am J Respir Crit Care Med 2004; 169: 994-1000.

13 Shovlin CL, Jackson JE, Bamford KB, et al. Primary determinants of ischaemic stroke/brain abscess risks are independent of severity of pulmonary arteriovenous malformations in hereditary haemorrhagic telangiectasia. Thorax 2008; 63: 259-266.

14 Shovlin CL, Tighe HC, Davies RJ, Gibbs JSR, Jackson JE. Embolisation of pulmonary arteriovenus malformations: no consistent effect on pulmonary artery pressure. Eur Respir J 2008; 32: 162-169.

15 Haitjema T, ten Berg JM, Overtoom TT, Ernst JM, Westermann CJ. Unusual complications after embolization of a pulmonary arteriovenous malformation. Chest 1996; 109: 1401-1404. 